\title{
Cytogenetics and Evolution in American Fragaria
}

\author{
Royce S. Bringhurst \\ Department of Pomology, University of California, Davis, CA 95616
}

\begin{abstract}
Fragaria $\times$ ananassa Duch., the modern cultivated octoploid strawberry $(2 n=8 x=56)$, is the culmination of all strawberry evolution as we know it. It was derived from the two American octoploid species: F. virginiana L., native to North America north of Mexico (primarily the Atlantic seaboard, Great Plains, and westem mountain ranges); and $F$. chiloensis Duch., native to west coastal North America and the west coast and Andes Mountains of South America. Both natural species are products of ancient polyploidization and natural selection. The modern cultivated strawberry $(F$. $\times$ ananassa) is of recent origin [in Europe between 1714 and 1759, according to Staudt (1962)], resulting from human intervention in the evolutionary process (Darrow, 1966). There is no convincing evidence that any of the lower ploidy level Fragaria spp. of Europe, Asia, or elsewhere were directly involved in the synthesis of the modern octoploid cultivars, as suggested by some (Wilhelm and Sagen, 1974)

In this paper, I attempt to establish that the evolutionary forces that gave rise to the present polyploids (particularly polyploidization and introgression), are still active in the narrow and fragile coastal fog belt of California today. Unless the evolutionary process is terminated by the imprudent destructive activities of humans, new ploidy levels may yet evolve with greater breadth of adaptation than that- of the present coastal octoploids. In addition, a significant amount of introgressive gene flow from the diploids into the octoploids without long-term changes in chromosome number is also likely.
\end{abstract}

\section{Genomic structure of the octoploids}

In the most recent comprehensive genomic study of the natural octoploids, Sennanayake and Bringhurst (1967) proposed the genomic constitution of AAA'A'BBBB (2A2A'4B). The 1967 study was based mostly on cytological comparisons of pentaploid (true polyhaploid, $2 \mathrm{n}=5 \mathrm{x}=35)$ and hexaploid $(2 \mathrm{n}=6 \mathrm{x}=42)$ octoploid $\times$ diploid hybrids. This proposal has been accepted generally.

I now suggest that the genomic structure of the octoploids ( $F$. $\times$ ananassa, $F$. chiloensis, and $F$. virginiana) be modified to AAA'A'BBB'B' (2A2A'2B2B') because of the compelling cytological (Byrne and Jalenkovic, 1976) and genetic (Arulsekar et al., 1981) evidence that they are highly diploidized.

\author{
Natural hybrids between $F$. chiloensis $\times F$. vesca
}

Twenty-seven years have elapsed since the first natural $F$. chiloensis $\times F$. vesca L. hybrids were discovered at Point Sur, Calif., and near Devils Slide above Montara, Calif. (Bringhurst and Khan, 1963). Since then, a relatively large number have been found randomly distributed up the California coast in seven of the places where the two species grow together, ranging from Point Sur on the central coast (lat. $36.4^{\circ} \mathrm{N}$ ) to Cape Mendocino on the north coast (lat. $41.2^{\circ} \mathrm{N}$ ). There is only one place south of Point Sur where $F$. chiloensis has been found to occur, Oso Flaco Lake (lat. $35^{\circ} \mathrm{N}$ ); this is a sand dune area where $F$. vesca does not survive (Table 1).

Most of the hybrids were the expected pentaploids $(2 \mathrm{n}=5 \mathrm{x}=$ 35 ) resulting from the combining of a normally reduced tetraploid female $F$. chiloensis gamete with a normally reduced haploid male $F$. vesca gamete (Fig. 1). However, two unusual hybrids were found (Bringhurst and Senanayake, 1966). One was a hexaploid $(2 \mathrm{n}=$ $6 \mathrm{x}=42$ ) that had to have resulted from the combining of a normally reduced tetraploid female $F$. chiloensis gamete with an unreduced diploid male $F$. vesca gamete (Fig. 2). The second unusual hybrid was an enneaploid $(2 \mathrm{n}=9 \mathrm{x}=63)$ presumed to have arisen from either the combination of an unreduced octoploid female $F$. chiloensis gamete with a normally reduced haploid $F$. vesca gamete, or from the combination of an unreduced pentaploid gamete from a pentaploid hybrid with a normally reduced tetraploid gamete from F. chiloensis (Fig. 3).

$F$. chiloensis is almost certainly the female parent of all $F_{1}$ hybrids between $F$. chiloensis and $F$. vesca, for two reasons. First, female $F$. chiloensis is heterogametic, segregating $1: 1$ for sex and the distributing of the hybrids as to sex fits a $1: 1$ ratio. Second, $F$. vesca ssp. Californica (Staudt, 1962) of coastal California is normally self-pollinating (Arulsekar and Bringhurst, 1981).

\section{Origin of natural decaploids}

Decaploidy $(2 \mathrm{n}=10 \mathrm{x}=70)$ is the next higher balanced euploid level in strawberries, and, given the information now available, may actually exist or may have existed in $F$. chiloensis populations already. We need only to consider the offspring of the natural pentaploid and hexaploid hybrids already discussed.

More than $60 \%$ fully fertile natural decaploid offspring came

Table 1. The seven locations and latitudes where natural hybrids of Fragaria chiloensis $\times F$. vesca have been found in coastal California, their relative importance, and prospects of survival.

\begin{tabular}{lclll}
\hline \hline Site & Lat. ${ }^{\circ} \mathrm{N}$ & Hybrids & Importance & Survival prospects \\
\hline Oso Flaco & 35.0 & None & Very high & Dim \\
Point Sur & 36.4 & Many & Highest & Fair to good \\
Montara & 37.1 & One & Moderate & Dim \\
Pacifica & 37.2 & Many $(5 \mathrm{x}, 6 \mathrm{x})$ & Highest & None, gone \\
Point Reyes & 37.9 & One & Moderate & Fair to good \\
Bodega Bay & 38.3 & Many & Highest & None, gone \\
Wrights Beach & 38.4 & One $(9 \mathrm{x})$ & High & Fair to good \\
Cape Mendocino & 41.2 & One & Moderate & Fair to good \\
Oregon border & 42.0 & $-\ldots$ & $\ldots$ & $\ldots$ \\
\hline
\end{tabular}




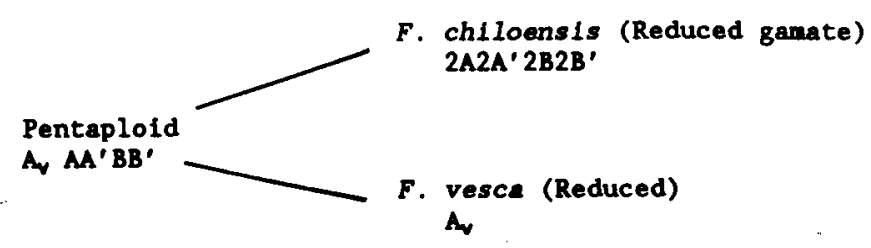

Fig. 1. Origin of natural pentaploid Fragaria hybrids from central California.

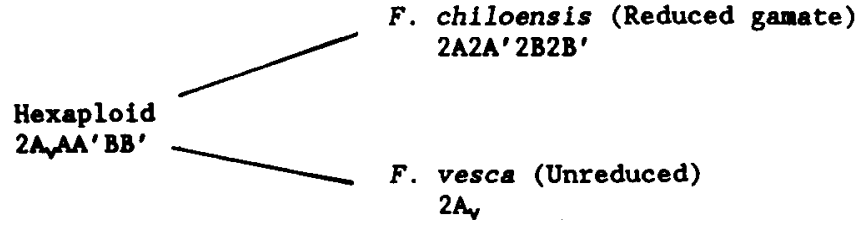

Fig. 2. Origin of natural hexaploid Fragaria hybrids from coastal California.

I.

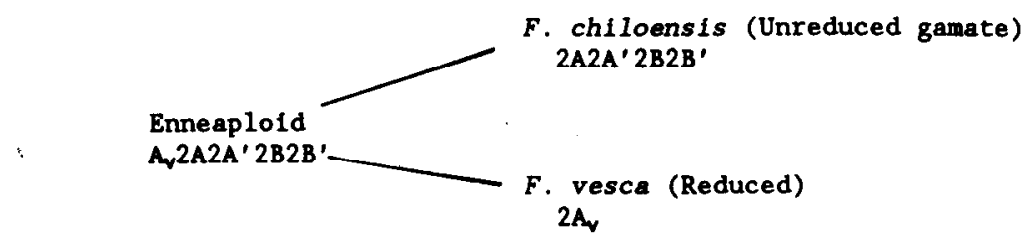

II.

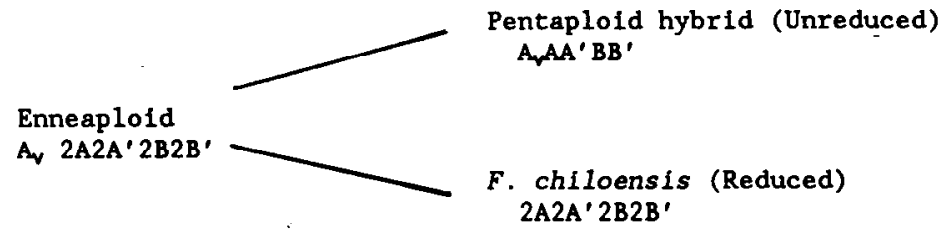

Fig. 3. Possible origins of natural enneaploid ( 9 ploid) Fragaria hybrids from coastal California.

I.

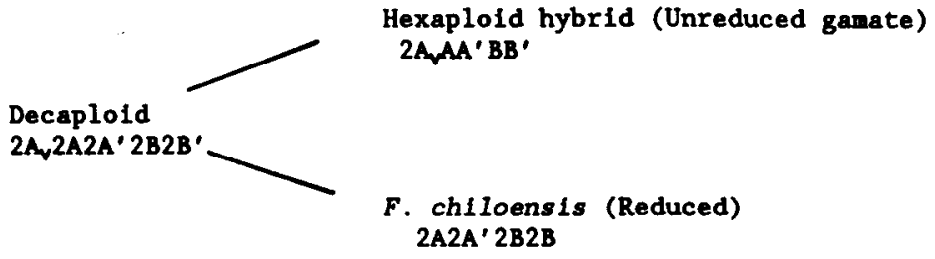

II.

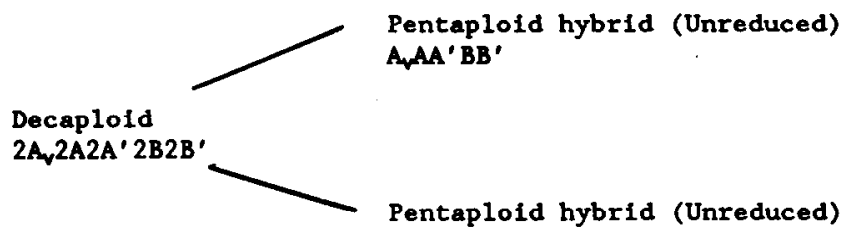

Fig. 4. Possible origins of natural decaploid Fragaria hybrids from coastal California.

from the natural hexaploid $F$. chiloensis $\times F$. vesca hybrid as a result of functioning unreduced hexaploid female gametes from the hybrid combining naturally with normally reduced $F$. chiloensis male gametes [Fig. 4 (top); Bringhurst and Gill (1970)].

Similarly, Scott (1951) synthesized fully fertile decaploids by crossing colchicine-induced tetraploid European 'Alpine' F. vesca with octoploid cultivars to get hexaploids that were partially fertile. These were then open-pollinated by cultivars to produce fertile decaploids through functioning unreduced gametes of the hexaploids.

The natural pentaploid hybrids, while not as fertile as the abovementioned natural hexaploid, still had a high enough level of fertility that a significant number of offspring were produced and $>80 \%$ of the offspring were from unreduced gametes. Thus, when two unreduced gametes were combined, the resulting offspring were fully fertile decaploids identical in every respect to those from the hexaploid described above [Table 4 (top); Bringhurst and Gill (1970)]. The pentaploid "male" hybrids from Bodega Bay tended to be hermaphroditic and self-fruitful; thus, a high percentage of the natural offspring there were fully fertile decaploid hermaphrodites.

\section{Introgression of genes from $F$. vesca to $F$. chiloensis}

The enneaploid (9x) hybrids were of great evolutionary and breeding interest because, although they carried a full set of unbalanced chromosomes, they were about as fully fertile as the natural decaploids and meiosis was characterized by normal reduced gametes. Thus, when the natural enneaploid backcrossed naturally to the octoploids (the usual case), the gametic chromosome number for the enneaploid offspring ranged from $\mathrm{n}=27$ to $\mathrm{n}=3.5$, with the largest class being $n=31$. The resulting enneaploids were fully fertile and a small percentage were actually octoploids in the first gener- 
ation (Bringhurst and Gill, 1970).

This indicates that the enneaploids, whatever their origin, may be an excellent vehicle for carrying specific genes from diploid species into the octoploids without the disruptive problem of accommodating to a new ploidy level in the process. Consequently, in breeding, the selection for target genes and against accompanying alien "junk" genes can be applied at an intensity not possible if going to the next higher ploidy level is required. The same principles would apply in the evolutionary process where natural selection is involved.

\section{Summary and conclusions}

There is little doubt that the ongoing polyploidization and introgression processes described here apply to the past as well as the present and future, indicating how natural polyploidization has taken place in Fragaria through the functioning of unreduced gametes. These successful hybrid colonies have now been observed for $>27$ years, and one can state with confidence that some specific hybrid colonies (e.g., Point Sur) have probably been there for $>100$ years and continue to thrive with reasonable vigor.

However, what of the future? Of the seven original hybrid colony sites, two of the three best (Pacifica and Bodega Bay) are gone forever, having fallen victims to coastline developments, and all of the others must be considered at relatively high risk. Specimens of most of the best hybrids, including the natural hexaploid and the most fertile pentaploid from Pacifica, the two best hermaphrodites from the Bodega Bay site, and the Wrights Beach enneaploid have been collected and some are established in the clonal Germplasm Repository, Corvallis, Ore.

An attempt should be made to reestablish some of the natural hybrids in as natural a situation as possible so that a study of the ongoing processes might be continued. However, it will not be the same as the undisturbed colonies, and steps should be taken to preserve certain of the colonies as intact as possible, particularly those at Point Sur.

\section{Literature Cited}

Arulsekar, S., R.S. Bringhurst, and V. Voth. 1981. Inheritance of PGI and LAP isozymes in octoploid cultivated strawberries. J. Amer. Soc. Hort. Sci. 106:679-683.

Arulsekar, S. and R.S. Bringhurst. 1981. Genetic model for the enzyme marker PGI in diploid California Fragaria vesca L.J. Hered. 73:117120.

Bringhurst, R.S. and T. Gill. 1970. Origin of Fragaria polyploids. II. Unreduced and doubled unreduced gametes. Amer. J. Bot. 57:969-976.

Bringhurst, R.S. and D.A. Khan. 1963. Natural pentaploid Fragaria chiloensis- $F$. vesca hybrids in coastal California and their significance in polyploid Fragaria evolution. Amer. J. Bot. 50:658-661.

Bringhurst, R.S. and Y.D.A. Senanayake. 1966. The evolutionary significance of natural Fragaria chiloensis $\times F$. vesca hybrids resulting from unreduced gametes. Amer. J. Bot. 53:1000-1005.

Darrow, G.M. 1966. The strawberry. Holt, Rinehart and Winston, New York.

Scott, D.H. 1951. Cytological studies on polyploids derived from tetraploid Fragaria vesca and cultivated strawberries. Genetics 36:311-331.

Senanayake, Y.D.A. and R.S. Bringhurst. 1967. Origin of Fragaria polyploids: I. Cytological analysis. Amer. J. Bot. 54:221-228.

Staudt, G. 1962. Taxonomic studies in the genus Fragaria, typification of Fragaria species known at the time of Linnaeus. Can. J. Bot. 40:870886.

Wilhelm, S. and J.E. Sagen. 1974. A history of the strawberry. Univ. of California Div. Agr. Sci. Berkeley. 